\title{
Compressed air injury of the eye
}

\author{
R. HITGHINGS And J. I. MaGiLL
}

Western Ophthalmic Hospital, London

Compressed air is commonly used in industry and injuries from it are frequent, but an extensive survey of the literature revealed no reports of injury to the eye caused by compressed air alone. Such a case is reported below and the various principles involved in its treatment are discussed.

\section{Case report}

A 29-year-old engineer fell over a compressed air hose he was carrying, with the result that a high-pressure air stream, at $8 \mathrm{o} \mathrm{lb}$. per square inch, was directed towards his left eye from a range of a few inches. He was brought to the hospital 20 minutes later.

\section{Examination}

The visual acuity was $6 / 9$ in both eyes. There was surgical emphysema of the lid and conjunctiva of the left eye, closing the palpebral fissure (Fig. I). No entry wound in either the conjunctiva or the eye was seen, nor was there any evidence of ocular injury. Ocular movements were restricted, principally those of abduction and elevation in the left eye, resulting in diplopia in all positions of gaze. The Hess chart showed no localized muscle weakness.

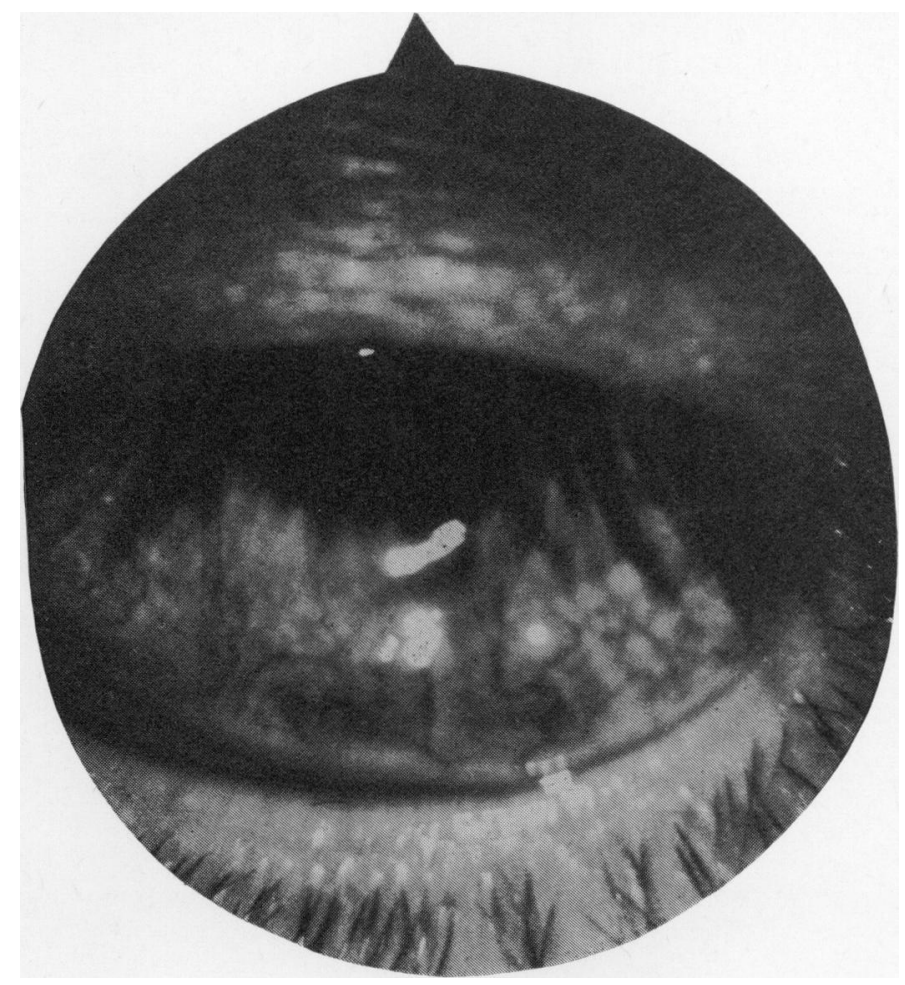

FIG. I Appearance of injured eye at first examination 
$X$ ray showed delineation of the globe by air (Fig. 2), but tomograms showed no ethmoid fracture or blow-out fracture of the orbital floor.

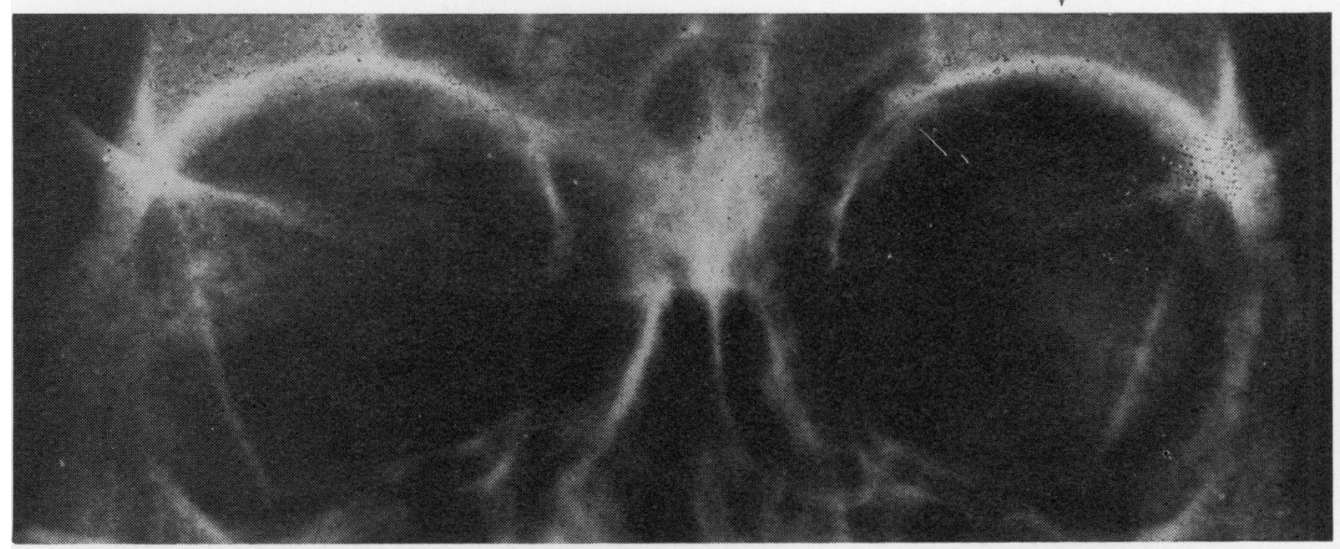

FIG. 2 Radiograph of orbits, showing the left globe surrounded by air (arrows)

\section{Treatment}

He was given systemic and topical antibiotics, and within 4 weeks the diplopia and emphysema had resolved completely.

\section{Discussion}

In every case of orbital emphysema associated with trauma, a fracture of the ethmoid bone should be considered. In this case it seems that the emphysema was due primarily to the high-pressure jet of air and not to a blow-out fracture of the orbital floor or a fracture of the ethmoid bone.

No entry wound was discovered, but the extremely tight apposition of the lids to the globe precluded detection of conjunctival rupture in the fornices.

Any high-pressure injury to the orbit can be dangerous in several ways:

(I) Contusion injury to the orbital contents;

(2) Intraocular or intraorbital foreign body;

(3) Inflammation secondary to infection or to a retained foreign body (e.g. grease-gun injuryDallas, 1968);

(4) A jet of air could cause a displacement of the orbital contents, with either a blow-out fracture or a forward protrusion of the globe;

(5) The intraorbital air may enter the cranial cavity by the way of the optic nerve sheath or through a fracture of the orbital wall (Tenner and Trokel, 1968).

This case illustrates yet another industrial hazard, highlighting the necessity for correct ocular protection; it provides a useful reminder of the possible ocular risks involved in handling seemingly innocuous tools.

We are grateful to Mr. R. A. Burn for permission to publish this case.

\section{References}

DAllas, N. L. (1964) Brit. F. Ophthal., 48, $15^{8}$

TENNER, M. S., and Trokel, s. L. (1968) Arch. Ophthal. (Chicago), 79, 572 